\title{
THE COLONIZATION OF EPILEPTICS. ${ }^{1}$
}

BY FREDERICK PETERSON, M.D.,

Attending Physician to the New York Hospital for Nervous and Epileptic; Lecturer on Nervous and Mental Diseases at the New York Polyclinic and Vanderbilt Clinic.

$\mathrm{I}^{\mathrm{N}}$

$\mathrm{N}$ I887 I wrote an account of a visit I had a short time previously paid to the Bethel Epileptic Colony at Bielefeld near Hanover in Germany ; ${ }^{2}$ and I have long desired to give a more comprehensive description of that institution, and to agitate the establishment in this country of a somewhat similar charity under the government of a State or at the instigation of private philanthropy. For every other defective class provision has been made in greater or less degree, for the insane, for idiots, for the deaf and dumb and blind, for the sick and the crippled, for the aged and infirm, for young malfactors in reformatories, for the negro and for the Indian-and for all of these, improvement in care, treatment or development is continually progressing.

Almost alone, however, has the sufferer from epilepsy been left to shift for himself, usually an outcast from his family, expelled from the schools, denied industrial employment, shunned to a great extent by his fellows, left to grow up in idleness and ignorance, friendless, a prey to one of the most dreadful and most hopeless of human ills, refused admission to general hospitals, generally drifting at last to the almshouse and insane asylum. He is given refuge in the insane asylum, not as a rule because he is deprived of reason, although many epileptics do become demented or unmanageable, but because there is no other place for him to go. Hundreds, nay thousands, of epileptics are in American asylums at this moment, who do not really

${ }^{1}$ Read before the Section on Public Health, etc., of the New York Academy of Medicine, Dec. 6, I889.

2 New York Medical Record, April 23, 1887. 
belong there, and of whom many will be found who show not even the slightest mental aberration. It is an injustice to the epileptic, and it is a detriment to the insane.

When we take into consideration that a large proportion of these unfortunates are gifted with as much intelligence as ordinary human beings, that they are as capable of education, as well adapted for ind ustrial pursuits, quite as able to be self-supporting as most people, the unutterable woes of this class become more apparent.

The conditions under which they may secure their proper mental development and their meed of occupation, must be such as combine medical supervision with wise industrial teaching and training. Society has here to perform a sadly neglected duty.

Actuated by such considerations some twenty-four years ago, a Lutheran clergyman, Pastor von Bodelschwingh, purchased a farm in the suburbs of Bielefeld, and with four epileptics as a beginning, established a colony, which for nobility of conception and excellence of results is unique in our civilization.

It seemed to this benignant man that it was feasible to create a refuge where these sufferers might be cured, if curable; where their disease might be ameliorated, their intellectual decay prevented; where they might have a comfortable home if recovery were impossible; where they might develop their mental faculties to the utmost; might acquire trades, or engage in whatever occupation they cared to choose ; finally growing into a community of educated, useful, industrious, prosperous and contented citizens. From that small beginning there has been a gradual evolution and expansion of the colony. In 1878 it had 250 epileptics; in 1880,458 ; in 1882,556 ; in 1886,830 ; and at the time of this writing considerably over 1,000 .

During the twenty years from 1867 to $1887,2,407$ epileptics had been received and treated at the colony. Of these I 56 or $6 \frac{1}{2}$ per cent. were discharged recovered, and over 450 improved.

But the dispensation of good by the colony is not limited to its immediate inhabitants, for upon application, with 
or without payment, medicines are sent to epileptics in every part of the world, without regard to sect or nativity, and the enormous extent of this export of remedies may be appreciated from the fact that 800 pounds of potassic bromide are now consumed per month by residents and correspondents. Some 48,000 epileptics have been beneficiaries of this charity.

EDUCATION AND EMPLOYMENT.-The industrial pursuits at Bielefeld are numerous and varied. Occupation not only ameliorates the mental and physical condition of epileptics, but the incurably afflicted are offered opportunities for culture and callings not attainable anywhere except in institutions of this character.

The Bielefeld Colony now consists of 55 houses, 150 families and over 2,000 inhabitants, inclusive of teachers, nurses, industrial trainers, co-laborers and patients. The arrangement of these houses can be seen in the accompanying plan. It will .be observed that the colony has little or nothing about it to suggest an institution, but is rather similar to a country village, with its variegated cottages and pretty gardens and farms. The houses are scattered over 320 acres of beautiful woodland and meadow. A synopsis of the uses of most of the buildings is given below :

\section{Female Division.}

2 cottages for patients of the better class.

I house for feeble-minded women and girls.

r house for half-demented girls.

I house for convalescent girls.

I4 houses for school children and workers.

\section{Male Division.}

2 houses for patients of the better class.

I house with 3 schoolrooms for boys and youths.

9 houses for hand-workers.

4 houses for gardeners and farmers, with gardens, farms and brick-kiln.

5 houses for more or less demented patients, 2 of which are for those still able to work. 


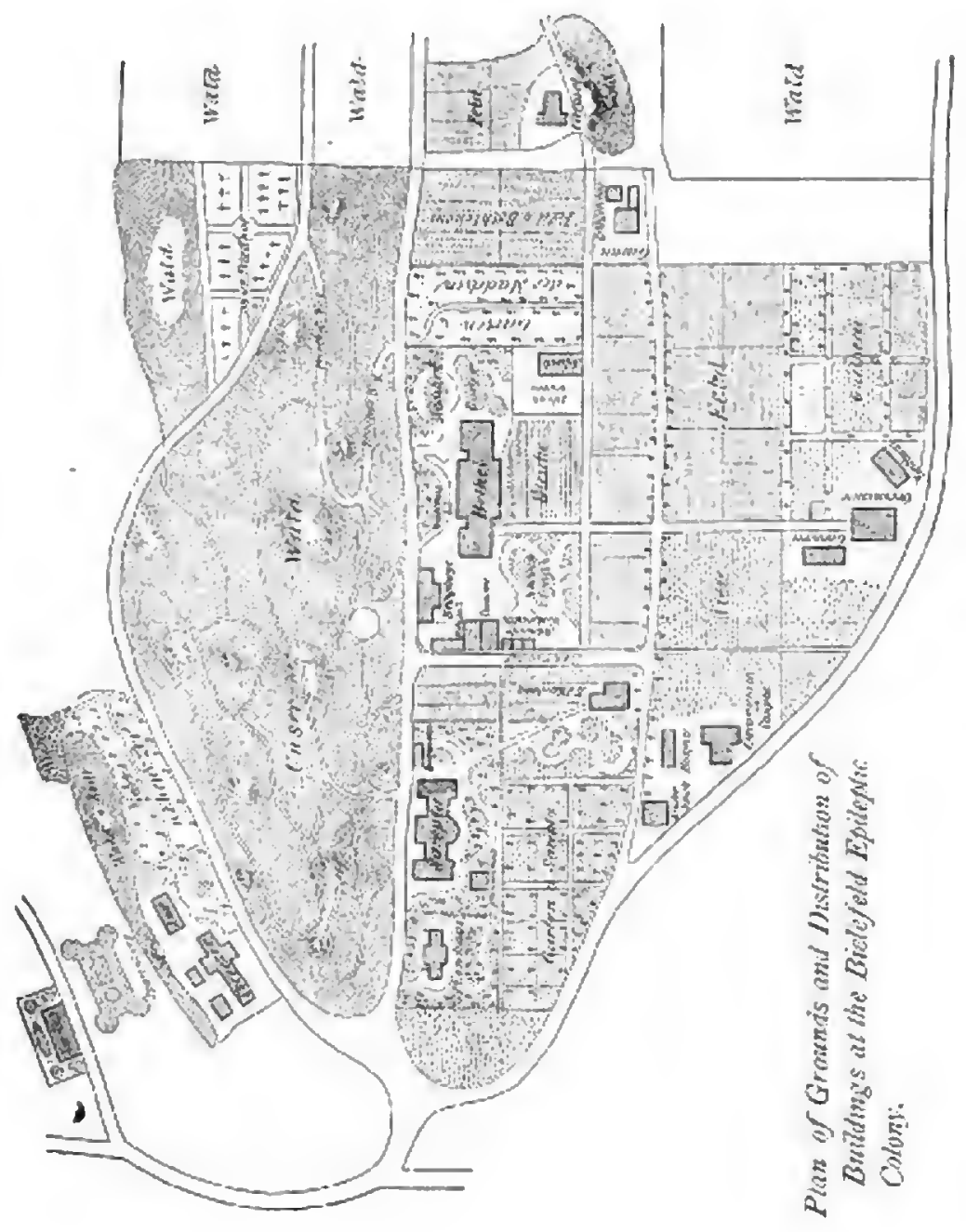


One of the chief features of the colony is the system of decentralization, the division of the patients as much as possible into small families, occupying cottages, the separation of the sexes, of the feeble-minded from those with normal mental faculties, separation according to age, social standing, former occupations, etc.,-a system likewise applicable, I may say, to the insane in the ideal psychopathic hospitals of the future, and already to some extent applied in the Saxon institution Alt-Scherbitz, and in the new Manicomio di Roma.

For the purpose of securing a sufficient number of male and female nurses, and of a superior order of kindly and sympathetic care, it was deemed expedient to found at the Bielefeld Colony also nurses' training schools, and as a result of this, not only have they well-trained brothers and sisters forming an order of deacons and deaconesses for their own use, but they have been enabled to supply various hospitals and insane asylums with a high class of caretakers. For my own part, and from my experience in institutions, I shall always feel that the highest order of care and nursing for such unfortunates as the insane and epileptics can only be obtained by the employment of those who enter upon these most arduous of duties from a deeply religious motive.

To observe more closely the variety of employments in vogue, one must make a personal visit to this remarkable colony, which I did in the Winter of I886-'87.

We find here schools in which instruction is given in all the branches usually taught in ordinary public schools; and to those who desire these, opportunities for higher studies in languages, arts and sciences are granted, many of the richer patients even employing private tutors for this purpose.

In the sewing-room, singing or being read to, may be seen sixty or more young women, making and repairing clothing, knitting stockings, doing useful fancy work, manufacturing wearing apparel and bed clothes.

In the kitchen and in the vegetable garden they may be seen busy with the preparation of meals, and the proper 
rearing of garden produce. The bedrooms, dormitories and dining-rooms, the laundries, drying and ironing-rooms, furnish occupation for a very large number of other women.

The men naturally have greater variety of employment. There are the book store, printing establishment and book bindery; a room for those who delight in illuminating picture-cards and mottoes for mural decoration, a favorite art everywhere in Germany; at the bindery, pictures are framed, books bound, envelopes made, and some leather work done; the books printed are in particular popular works for the dissemination of moral and religious instruction; twenty men are employed at this work. Floriculture, agriculture and fruit-raising require large numbers of employees, particularly so, since so much flower and vegetable seed-produce is garnered, put in packages and shipped and sold from their own seed-store.

A joinery, bakery, tailor-shop, paint-shop, locksmithshop, blacksmith-shop, foundry, tin-shop, shoe-shop, saddlery, dairy, brick-yard, drug-store and grocery, all provide occupation to numberless inhabitants of this colony, even to some suffering also from old hemiplegias.

Some of the houses have been planned by epileptic architects, the brick made by sixty epileptic patients at the brick-kiln, the masonry done by epileptic workmen, the woodwork made by their own carpenters, the ironwork by their own smiths, the painting, glazing, furnishing by their own adepts in these various trades.

For men alone there are over thirty different callings.

From this it will be seen how noble was the conception of this truly philanthropic institution. And not only in manifold employment has the genius of its conceiver been made manifest, but in all things that might tend to distract the minds of the patients from themselves and their misfortunes. Games and amusements are many, walks in the gardens, out-of-door sports, evening entertainments, singing schools, an orchestra made up from their own number, a museum for the collection of stamps, coins, gems, autographs, bronzes, antiquities, articles of ethnographic or historical interest, and specimens from the animal, vege- 
table and mineral kingdoms-all have been carefully thought out for the perfect evolution of this little social world.

When the evil disorder attacks one in the field or garden, willing hands are near to attend to him, and every workshop has its mattress within convenient reach on occasions of emergency.

To sum up the objects of this colony, it is in the first place a hospital for the cure of epilepsy, and attempts at cure are made upon every patient without exception. It is a school for the instruction and education of epileptic children. It is an industrial institute for epileptic youths and adults. It is an asylum for those who become demented from the effects of the disease.

Although the colony is under the domination of the church, and has a Lutheran pastor at its head (I do not know that a physician or ordinary layman with his more sordid purposes would be as efficient a superintendent), three physicians are employed to supervise the medicinal treatment, one of whom is resident in the colony.

TREATMENT OF EPILEPSY.-It is to be expected that something should have been learned of the best methods of treating this disease after an experience of so many years with such immense numbers of patients. As a result of the experience of the colony, the following is the course now pursued:

x. Employment of mind and body.-This is paramount. Out-door work is best. It has already been shown how admirable is this therapeutic feature in the Bielefeld colony.

2. Restrictions in diet.-Food must be plain, not rich, and little acid. Spirituous liquors are to be avoided. (Smoking is allowed in moderation.) Coffee and tea must be weak and mixed with much milk. A good milk diet is preferable to meats or soups. Supper should be early and light.

3. Baths.-Cold shower baths gradually prolonged, and cold sponge baths are beneficial.

4. Drugs.-Everything recommended in the pharmacopeia has been tried as to its efficiency in this disease, and 
nothing found to succeed so well as the bromide of potassium alone. All of the bromide salts have been experimented with both singly and in combination, and though the mixed bromides are often of great value, the potassic salt has in every respect proved to be the most satisfactory. It has been found that most patients can take it year after year without gastric disturbance. It cures some cases, lessens the frequency of seizures in most, soothes the excited nerves, and serves to diminish the tendency to mental enfeeblement. The usual prescription is

$$
\begin{aligned}
& \text { P. Pot. brom., - - - } 20 \text { grammes, (3 v.) } \\
& \text { Aquæ puræ, - - - } 200 \quad \text { " (3 vi.) }
\end{aligned}
$$

SIG.-Take one tablespoonful three times daily, immediately after eating, for the first week.

If the seizures diminish in frequency, keep to the same dose; if not, increase to four tablespoonfuls daily in the second week, five in the third week, and so on until eight such doses are taken daily if necessary. If eight prove injurious mentally or cause severe eruptions, particularly on the legs, the dose is again gradually diminished. In many cases minimal doses only are borne and should then be persisted in for indefinite lengths of time. The above dosage is for patients over sixteen years of age. From ten to sixteen, begin with three tablespoonfuls, but do not exceed five or six. Under ten years begin with two such doses daily and increase to four. Very young children should be given still less.

Particular pains should be taken to procure a thoroughly pure drug, as the bromide generally sold contains impurities, such as chlorate of potash and other foreign substances, often to the extent of six per cent. An especially pure drug is prepared for this colony, containing not above 0.5 to 0.7 per cent. of foreign matter.

Even after the cessation of attacks the remedy should be persisted in with gradually lessening doses, for as long as eight to nine months.

Other Colonies for Eprleptrcs.-Sine the successful establishment of the Bielefeld colony, a number of 
similar institutions for epileptics have sprung into existence on the Continent, particularly in the various provinces of the German Empire. Among these are Rotenburg also in Hanover.

Mariahilf near Munster and Olpe in Westphalia.

Alexianer-Kloster at Aix-la-Chapelle and Rath near Düsseldorf for the Rhinish province.

Neinstedt-Thale for Saxony.

Tabor near Stettin for Pomerania and Posen.

Karlshof near Rastenburg for East and West Prussia.

Potsdam for Brandenburg.

Haarlem in Holland.

Zürich in Switzerland.

Thus the beneficent work is extending im many directions, and surely it is time that philanthropic minds should in this country also turn their attention to one of the most unhappy classes of our people, a class more deserving of commiseration, more deserving of the title of "the children of the State" than many vicious classes whom we endeavor, usually vainly, to reform in large government institutions.

At the usually accepted ratio of two epileptics per thousand of population, the United States have much over one hundred thousand persons suffering from this disorder, the circumstances and condition of most of whom are such as have been described. There is probably not an almshouse or asylum in any county of this Union but has a few or many epileptics among its inmates. As far as I know there is no institution in this country existing especially for this class, save the small beginning recently made by the State of Massachusetts in converting a private asylum for epileptics into a public one subsidized by the Legislature. The New York City Hospital for nervous and epileptic, on Blackwell's Island, of which I am one of the attending physicians, is hardly to be called a hospital for this class alone.

In New York State there are some 12,000 epileptics. The poorer classes have drifted to a large extent into public institutions, chiefly almshouses. In the more important State asylums there are now about 300 . Utica has 2I, 
Binghamton 80, Middletown 19, Willard I60, and Buffalo 22. They are far from desirable patients to associate with the insane, and are taken into these institutions only because there is no other place for them. They are received under a sort of compulsion.

Dr. J. B. Andrews, superintendent of the Buffalo State Asylum, writes me: "I should prefer a separate institution, especially for the younger class of epileptics."

Dr. G. Alder Blumer, superintendent of the Utica State Asylum, writes me: "In my opinion there should be a special State custodial institution for epileptics."

Dr. T. S. Armstrong, superintendent of the Binghamton State Asylum, writes me: "We have thought there should be a separate institution for this class. We find epileptics often have a depressing influence upon our other patients."

Dr. S. H. Talcott, superintendent of the Middletown State Asylum, writes me: "Epileptics should not, in my judgement, be admitted to general asylums for the insane. Hospitals should be constructed especially for their needs."

New York City which is largely representative of every thing in the Union, is also representative of what the Republic has done, or rather has failed to do, to mitigate the misfortunes from which this class suffer more than any other. In the first place a great proportion of epileptics are cared for in their own homes, wretched as these may be, and seek in large numbers the consolation of treatment at our city dispensaries. I know personally of perhaps a hundred who are or have been regular attendants in the Nervous Departments of the Vanderbilt Clinics and Polyclinic within the past year.

When even this doubtful solace of idly living at home, without education or employment, and of frequenting the dispensaries, cannot be continued, the City reluctantly extends to them its hospitality-the hopeless comfort of its almshouse and its numerous asylums. There are large numbers of epileptics in the almshouse on Blackwell's Island. My wards in the Nervous Hospital contain some fifty within its cheerless walls. There are large numbers in the Women's Insane Asylum on Blackwell's Island, in the 
Men's Insane Asylum on Ward's Island, and other of the City's capacious charities open to them some sort of refuge from the world's calamities and distress. But the utter inadequacy of such institutions to the needs of the epileptic is too apparent to require further word of mine.

This essay has been written in the hope that some public sentiment may be aroused as to the necessities of this neglected class of defectives, in the hope that it may prevail upon some religious sisterhood, some private philanthropist or some public official to provide for the early establishment in this or some other State of an epileptic colony, which shall become a home for the homeless, a place of refuge from many miseries, an educational institute for those who are forbidden the public schools, an industrial college for those to whom the ordinary avenues of trade are closed, a hospital where cure or palliation shall be possible, and where the highest scientific minds may be enabled to discover sometime a specific against one of the most woful of human ills; in short, a prosperous, industrious and thriving community, to serve as a model for many other such yet to be founded on this continent.

20I West 54th Street. 